\title{
Characterisation of $\mathrm{BHK}-21$ cells engineered to secrete human insulin
}

\author{
Patrick Gammell, Lorraine O'Driscoll* and Martin Clynes \\ National Institute for Cellular Biotechnology, Dublin City University, Glasnevin, Dublin 9, Ireland; *Author \\ for correspondence (e-mail: lorraine.odriscoll@dcu.ie; phone: +353-1-7005700/5402; fax: +353-1- \\ 7005484)
}

Received 29 May 2002; accepted in revised form 6 October 2002

Key words: BHK21, Cell Therapy, Diabetes, Glucokinase (GCK), Glucose Sensing, Glucose transporter type 2 (GLUT2), Human Insulin Gene, Insulin secretion, Multigene expression

\begin{abstract}
Autoimmune destruction of $\beta$ cells in the pancreas leads to type I, or insulin dependent diabetes mellitus (IDDM), through the loss of endogenous insulin production capacity. This paper describes an attempt to generate 'artificial' $\beta$ cells using the fibroblast cell line BHK21. Stable transfectants expressing the human preproinsulin (PPI) gene were isolated and characterised. The resulting clone selected for further analysis (BHK-PPI-C16) was capable of secreting $0.12 \mathrm{pmol}$ proinsulin $/ \mathrm{hr} / 10^{5}$ cells and maintained a steady cellular proinsulin content of $0.36 \pm 0.04$ pmol $1^{-1}$. There was no processing of the proinsulin to mature insulin. The cells were unresponsive to glucose but there was increased proinsulin secretion in the presence of agents that stimulated formation of intracellular cAMP. Transfection of cDNAs for the key elements of the glucose sensing apparatus (GLUT2 and glucokinase) led to a subphysiological stimulation of secretion when glucokinase was transfected alone while there was a complete loss of insulin secretion when both components were overexpressed. The deleterious effect on proinsulin secretion observed upon co-expression of the glucose sensing genes may have implications for applications requiring multigene expression in BHK21 cells.
\end{abstract}

\section{Introduction}

Diabetes Mellitus (Type I diabetes) is the direct result of the autoimmune destruction of insulin producing $\beta$ cells in the pancreas. Traditional treatment of diabetes by direct injection of insulin does not provide the continuous regulation of insulin levels that is normally effected by $\beta$ cells in response to fluctuations in blood glucose levels. An ideal therapy for the disorder would involve the implantation of cells which secrete insulin in response to physiologically relevant elevations in blood glucose levels in order to maintain normoglycemia.

Non- $\beta$, immortalised cell lines have been utilised in experiments to generate replacement or artificial $\beta$ cells. These cells are available in large numbers and represent a self-replicating source of transplant material. The fact that the cells are not $\beta$ cells is also advantageous, as they might not express all of the cell markers/antigens that led to the autoimmune destruction of the host $\beta$ cells.

Previous studies have used hepatocytes, neuroendocrine cells, CHO cells, and fibroblasts (Simpson et al. 1995; Motoyoshi et al. 1998; Kintsurashvili et al. 1998; Taniguchi et al. 1997). These have exhibited varying levels of success, however none have as yet been considered as suitable material for human therapy.

Secretion of processed insulin was achieved in the neuroendocrine cell line AtT-20 (Hughes et al. 1991). The prohormone convertase enzymes PC2 and PC3 facilitated processing of the proinsulin. These cells demonstrated regulatable secretion when stimulated by dibutyryl cyclic adenosine monophosphate ( $\mathrm{db}$ cAMP) but did not exhibit glucose stimulated insulin secretion (GSIS), thus the cells were seen to exhibit a regulatable insulin secretion pathway similar, in part, to that of $\beta$ cells. It was found that the cells naturally 
expressed glucokinase but lacked glucose transporter type 2 (GLUT2) expression (the other main component of the glucose sensing system in $\beta$ cells). Stable expression of GLUT2 cDNA in the AtT20-Ins cells led to GSIS although it was at subphysiological levels (Hughes et al. 1992). Motoyoshi et al. (1998) demonstrated GSIS over the whole physiological range with AtT20 cells by the co-transfection of GLUT2 and glucokinase. While these cells are approaching the ideal for an artificial $\beta$ cell, the inherent secretion of adrenocorticotropic hormone (ACTH), from these cells is undesirable. ACTH can increase glucocortocoid levels in the body, which has been associated with insulin resistance (Stewart et al. 1994).

One of the first somatic therapy approaches to be taken involved the implantation of proinsulin secreting fibroblasts into diabetic mice (Selden et al. 1987). These engineered $\mathrm{Ltk}^{-}$cells constitutively released proinsulin. Implantation of the cells reduced the blood glucose levels of the test animals to normoglycemic levels within two weeks. The test animals subsequently died as a result of implant overgrowth leading to severe hypoglycemia. This effect was also observed by Kawakami et al. (1992). To control the overgrowth of implanted fibroblasts, they were entrapped in 5\% agarose which prevented the overgrowth of the cells for up to 80 days (Taniguchi et al. 1997). These entrapped fibroblasts were found to maintain normoglycemia in diabetic mice for an average of 30 days (the range was from 7 to 50 days). Initial studies with fibroblasts have all involved unprocessed proinsulin and in each normoglycemia was achieved via constitutive secretion. Proinsulin is bioactive, however its activity is $8 \%$ (Taniguchi et al. 1997) to $20 \%$ (Falqui et al. 1999) of mature insulin. While steady release of insulin has been shown to aid in controlling normoglycemia in diabetes mellitus (Falqui et al. 1999), regulatable secretion would be far more desirable. Previous studies indicate that fibroblasts lack the cellular machinery for regulatable protein processing, storage and secretion (Kelly 1985; Halban and Irminger 1994). Processing of proinsulin in fibroblasts has been overcome by mutating the proinsulin cDNA so that it would be cleavable by the ubiquitous endoprotease furin (Falqui et al. 1999). Regulation of proinsulin secretion from fibroblasts has also been achieved, although at the transcriptional level by the use of a mMT1 promoter (Kawakami et al. 1992). This promoter was positively regulated in the presence of divalent cations such as cadmium.
In this study BHK-21 cells were chosen as a recipient cell line for the human insulin gene. These cells have already been employed in a trial for amyotrophic lateral sclerosis (ALS) where they were modified to secrete ciliary neurotrophic factor (CNTF) (Aebischer et al. 1996). Thus these cells are already characterised as being safe to implant into humans. In addition to the human insulin gene, the glucose sensing genes, GLUT2 and glucokinase, were transfected in an attempt to confer regulated secretion on the cells.

\section{Materials and methods}

\section{Cell line culture}

BHK-21 cells (ATCC CCL 10) were grown in modified Eagle's medium (MEM) with $5.6 \mathrm{mmol} \mathrm{l}^{-1}$ glucose, $1 \%$ L-glutamine, $1 \%$ non-essential amino acids and 5\% FCS. DLKP (a cell line established in our laboratory from a poorly differentiated lung squamous cell carcinoma) was routinely cultured in DMEM: Hams F12 = 1:1 supplemented with 5\% FCS, $1 \%$ sodium pyruvate and $2 \mathrm{mM}$ L-glutamine (Law et al. 1992). The murine $\beta$ cell line, Min6, was cultured in DMEM supplemented with $20 \%$ serum (heat inactivated at $56{ }^{\circ} \mathrm{C}$ for $35 \mathrm{~min}$ ). DLKP were cultured at $37{ }^{\circ} \mathrm{C}$. BHK-21 and Min6 cells were cultured at $37{ }^{\circ} \mathrm{C}$ in an atmosphere of $95 \%$ air, $5 \%$ $\mathrm{CO}_{2}$. Routine sterility checks, including screening for Mycoplasma, indicated that the cells were clear of contamination.

\section{Plasmid constructs}

Human preproinsulin (PPI) coding region (333 bp) was cloned from a pancreatic cDNA library and inserted into pTarget mammalian expression vector (Promega; Southampton, England), conferring geneticin resistance, resulting in the PPI construct (pT-PPI plasmid). Sequencing was carried out to ensure no mismatches were included. Human GLUT2 cDNA (P-7-GLUT2), a gift from Prof MA Permutt, Washington University School of Medicine, St. Louis, as full length coding sequence of human islet glucose transporter in puC19 vector, was subcloned from the KnpI-XbnI site and inserted into pcDNA3.1/Zeocin (Invitrogen; Groningen, The Netherlands), resulting in ZeoGLUT2 plasmid; human glucokinase (GCK) cDNA (phIGLK-2), a gift from Prof MA Permutt as 
full length coding sequence of human islet GCK cDNA in pBluescript $\mathrm{SK}^{+}$vector, was subcloned into pcDNA3.1/Hygromycin (Invitrogen), resulting in HygGCK plasmid.

\section{Stable transfection of cell lines}

BHK-21 cells were seeded at $2 \times 10^{5}$ cells per $25 \mathrm{~cm}^{2}$ flask 24 hours prior to transfection. LipofectAMINE PLUS $^{\mathrm{TM}}$ reagent (GibcoBRL, Life Technologies; Paisley, Scotland) was used for all transfections. Human PPI (pT-PPI plasmid) was transfected alone into BHK-21 cells. Clonal populations (resistant to 1 $\mathrm{mg} \mathrm{ml}^{-1}$ of geneticin) resulting from pT-PPI plasmid transfections were further co-transfected with GLUT2 and GCK which were selected with zeocin (100 $\mu \mathrm{g} \mathrm{ml}^{-1}$ ) and hygromycin $\left(150 \mu \mathrm{g} \mathrm{ml}^{-1}\right)$, respectively.

\section{RT-PCR analysis}

For RNA analyses, cells were grown in $75 \mathrm{~cm}^{2}$ tissue culture flasks until approximately $80 \%$ confluency was reached. Total RNA was isolated from pelleted cells by extracting with TriReagent (Sigma; Poole, England) according to the manufacturer's instructions. First-strand cDNA was synthesised from $1 \mu \mathrm{g}$ RNA using oligo dT primers (Oswel; Southampton, England). $5 \mu \mathrm{l}$ cDNA was then amplified in a $50 \mu \mathrm{l}$ PCR reaction solution containing $1.5 \mathrm{mmol}^{-1}$ $\mathrm{MgCl}_{2}, 0.2 \mathrm{mmol} \mathrm{l}^{-1}$ deoxynucleotide triphosphates, $20 \mu \mathrm{mol} \mathrm{l}^{-1}$ oligonucleotide primers and 2.5 U Taq polymerase enzyme (Sigma). Forward and reverse primers used for cDNA amplification were as follows: PPI (forward): 5' AGCGTGGCTTCTTCTACACACC $3^{\prime}$ and (reverse) 5' GGTGCAGCACTGATCCACAATG 3' amplifying a 158 bp product; GLUT2 (forward): $\quad 5^{\prime}$ TGGCAGCTGCTCAACTAATCAC $3^{\prime}$ and (reverse) 5' AAACAGGTTTGCTGATACCAGC $3^{\prime}$ resulting in an amplified 759 bp product; GCK (forward): 5' GATGCTGGATGACAGAGCCAGGATG 3' and (reverse) 5' AGATGCACTCAGAGATGTAGTCGA 3' amplifying a 392 bp product; $\beta$-actin (forward): $5^{\prime}$ TGGACATCCGCAAAGACC$\overline{\text { TGTAC }} 3^{\prime}$ and (reverse) 5' TCAGGAGGAGCAATGATCTTGA 3' primers were used, together with GLUT2 and GCK primers, to amplify a 142 bp $\beta$ actin product. Forward: 5' GAAATCGTGCGTGACATTAAGGAGAAGCT 3' and (reverse): 5' TCAG-
GAGGAGCAATGATCTTGA 3' primers were included with PPI primers, resulting in amplification of a 383 bp $\beta$-actin product.

\section{Immunocytochemical analysis}

For immunocytochemical analysis, cells were grown in 6 well plates, rinsed three times with PBS and fixed at $-20{ }^{\circ} \mathrm{C}$ for $5 \mathrm{~min}$ in methanol, which had been pre-chilled to $-20{ }^{\circ} \mathrm{C}$. Primary antibodies used were as follows: insulin (Clone 5B6/6; monoclonal insulin/proinsulin rat antibody raised in mouse (Biogenesis; Poole, England); 1/300 dilution in Tris-buffered saline (TBS: $0.05 \mathrm{~mol} \mathrm{l}^{-1}$ Tris- $\mathrm{HCl}, 0.15 \mathrm{mmol}$ $1^{-1} \mathrm{NaCl}, \mathrm{pH}$ 7.4)). GLUT2 (AB1342: raised in rabbit; 1/300 dilution in TBS) (Chemicon, Harrow, England), GCK (GCK N-19, SC-1980: raised in goat; 1/30 dilution in TBS (Santa Cruz Biotechnology; Santa Cruz, CA)). Immunocytochemical analysis was performed using the avidin biotin-horse radish peroxidase (AB-HRP) technique (ABC visualisation kit) (DAKO Labs, Cambridgeshire, England), according to the manufacturer's instructions. Briefly, endogenous peroxidase activity was quenched using $3 \%$ $\mathrm{H}_{2} \mathrm{O}_{2}$. Non-specific binding was then blocked using dilute (1:5 in TBS) rabbit (for insulin and GCK analyses) or swine serum (for GLUT2 analysis), as appropriate. Primary antibodies were added and incubated for $2 \mathrm{~h}$ at $37{ }^{\circ} \mathrm{C}$ or over-night at $4{ }^{\circ} \mathrm{C}$. Secondary antibodies were added for $30 \mathrm{~min}$ at room temperature. This was followed by a further $30 \mathrm{~min}$ of incubation at room temperature with streptABC complex/HRP. HRP activity was visualised using a 3,3diaminobenzidine tetrahydrochloride (DAB) chromogen, which resulted in a brown colour precipitation.

\section{Western Blot analysis}

For Western blots, cells were harvested by trypsinisation and washed three times with PBS. Cells were then lysed in buffer containing $62.5 \mathrm{mmol} \mathrm{l}^{-1}$ Tris$\mathrm{HCl} \mathrm{pH} 6.8,12.5 \%$ glycerol, 2\% Nonidet P40 (Sigma), $2.5 \mathrm{mmol} \mathrm{l}^{-1}$ phenylmethylsulphonyl fluoride (PMSF) (Sigma), $1.25 \mathrm{mmol} \mathrm{l}^{-1}$ EDTA, $12.5 \mu \mathrm{g}$ $\mathrm{ml}^{-1}$ leupeptin (Sigma), $116 \mu \mathrm{g} \mathrm{ml} \mathrm{ml}^{-1}$ aprotinin (Sigma) for $40 \mathrm{~min}$ on ice, sonicated and protein was quantified by Bradford assay. $50 \mu \mathrm{g}$ aliquots of samples were separated by running at $250 \mathrm{~V}$ and $45 \mathrm{~mA}$ 
on a $10 \%$ polyacrylamide gel, proteins were transferred onto nitrocellulose membranes (using a semidry transfer cell (Biorad)), and, in the case of GLUT2, were blocked for 2 hours at room temperature with $5 \%$ semi-skimmed dried milk in TBS. For GCK analysis, membranes were blocked for 2 hours at room temperature with $2.5 \%$ semi-skimmed dried milk in TBS. Membranes were then probed overnight, at $4{ }^{\circ} \mathrm{C}$, with primary antibodies detailed in "Immunocytochemical Analysis", using appropriate dilutions (GLUT2, 1/5000; GCK, 1/100). Following a series of washes, the membranes were probed with an appropriate peroxidase-labelled secondary antibody for 1 hour and visualised by chemiluminescence using ECL reagents (Amersham Pharmacia Biotech.; Buckinghamshire, England).

\section{Proinsulin and insulin content and secretion}

Prior to insulin content and secretion analyses, $2 \times$ $10^{5}$ cells were seeded per well of 6-well plates and allowed to attach over-night. Following this, the cells were rinsed 3 times with PBS (pre-heated to $37^{\circ} \mathrm{C}$ ), to remove proinsulin and insulin secreted over-night, and were subsequently incubated in glucose-free medium for $2 \times 15 \mathrm{~min}$. To assess proinsulin and insulin cellular content and constitutive secretion, cells were then exposed to serum-free medium containing $0.1 \%$ BSA for $0,1,2,4,8$ and $24 \mathrm{~h}$ of incubation. Glucose-stimulated proinsulin and insulin secretion were assessed following exposure to $0,0.5$, $1,2,5,10,15$ and $20 \mathrm{mmol}^{-1}$ glucose in serum-free medium for $2 \mathrm{~h}$. Following all incubations, medium was collected for analysis. For measurements of intracellular proinsulin and insulin content, cells were lysed in lysis buffer $\left(20 \mathrm{mmol}^{-1}\right.$ Tris $\mathrm{pH} \mathrm{8.0,} 2$ mmol $1^{-1}$ EGTA, $1 \%$ Triton X-100, 10\% glycerol, 1.5 $\mathrm{mmol} \mathrm{l}^{-1} \mathrm{MgCl}_{2}, 137 \mathrm{mmol} \mathrm{l}^{-1} \mathrm{NaCl}, 1 \mathrm{mmol} \mathrm{l}^{-1}$ $\mathrm{Na}_{3} \mathrm{VO}_{4}, 1 \mathrm{X}$ protease inhibitor cocktail (Boehringer Mannheim; Germany), 5\% BSA). Proinsulin and insulin levels were measured by ELISAs. Proinsulin and insulin were co-detected using a Rat Insulin kit which is $120 \%, 71 \%$ and $<0.05 \%$ cross-reactive with human insulin, proinsulin and c-peptide, respectively (Mercodia AB, Uppsala, Sweden; 10-11-24-10). Mature insulin was assessed using a specific human insulin ELISA (Mercodia AB; 10-11-13-10) which is $<0.01 \%$ cross-reactive with proinsulin and c-peptide, following procedures provided by the manufacturers.

\section{Results}

\section{Cell lines}

Transfection of BHK21 cells with the pT-PPI plasmid resulted in 20 clones resistant to $1 \mathrm{mg} \mathrm{ml}^{-1}$ geneticin. Analysis of the clones resulted in the selection of Clone 16 (BHK-PPI-C16) for further analysis. Subsequent cell populations were generated by transfecting BHK-PPI-C16 with the pcDNA3.1-GLUT2 plasmid (including the zeocin resistance gene) and the pcDNA3.1-GCK plasmid (including the hygromycin resistance gene). Those cells successfully transfected (either with glucokinase alone or both plasmids) were selected in increasing levels of antibiotics (in combination where appropriate) to final selection concentrations of $150 \mu \mathrm{g} \mathrm{ml}^{-1}$ hygromycin, $100 \mu \mathrm{g} \mathrm{ml}^{-1}$ zeocin and $1 \mathrm{mg} \mathrm{ml}^{-1}$ geneticin. This led to two additional cell populations for analysis BHK-PPIC16-GCK and BHK-PPI-C16-GCK-GLUT.

\section{RNA analysis}

Expression of insulin, glucokinase, and GLUT2 mRNAs were confirmed by reverse transcriptase PCR (RT-PCR). Proinsulin transcripts were found to be present in the cell line BHK-PPI-C16 and were completely absent in the untransfected BHK21 cells. Similarly the newly constructed cell populations (BHK-PPI-C16-GCK and BHK-PPI-C16-GCKGLUT) were found to contain PPI transcripts (Figure 1A). Human glucokinase mRNA and GLUT2 mRNA were transcribed in the cell populations resulting from the transfection of BHK-PPI-C16 with these cDNAs (Figures 1B and 1C, respectively). There were low levels of these mRNAs already in the cells not transfected with the GLUT2 and glucokinase cDNAs, i.e., BHK21 and BHK-PPI-C16. $\beta$-actin (383 bp or 142 bp depending on primer pair used) was used in all cases as an endogenous control for RNA quantity and quality.

\section{Immunocytochemical analysis}

Results from expression of proinsulin, GLUT2 and glucokinase were determined by immunocytochemical analysis, as shown in Figure 2. Transfection of PPI resulted in the translation of the protein in the cytoplasm of BHK-PPI-C16, while there was an absence 


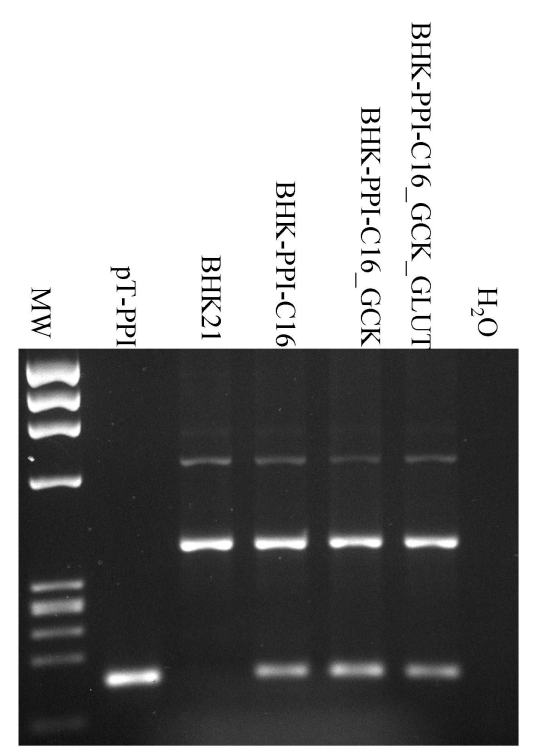

A

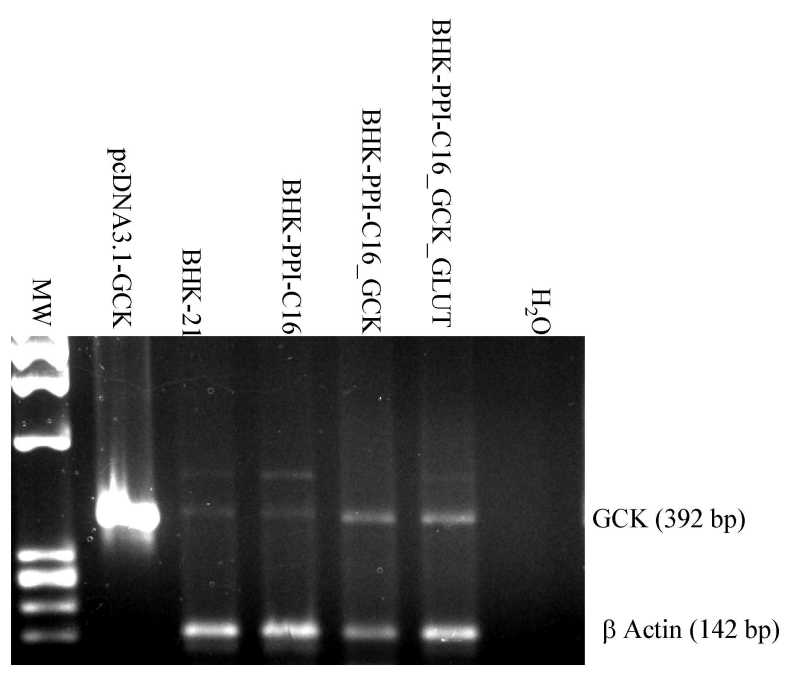

B

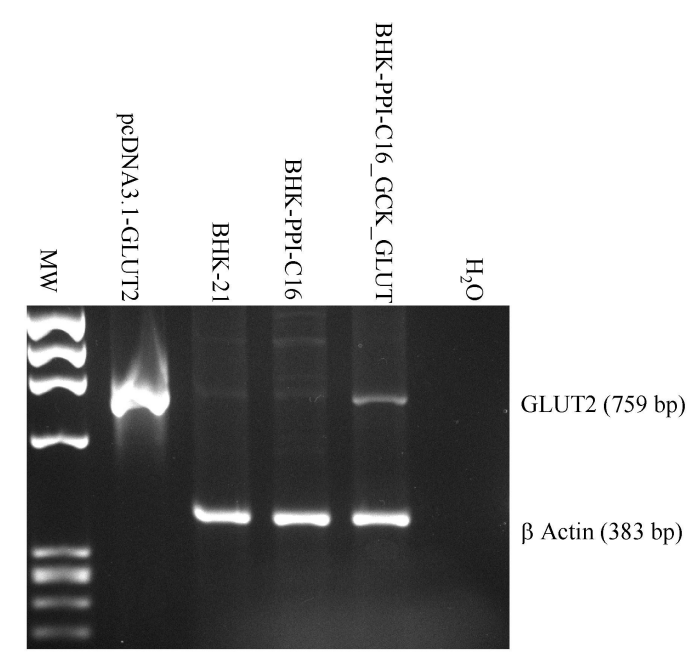

B

Figure 1. RT-PCR analysis of (A) Human PPI (B) glucokinase and (C) GLUT2 mRNA transcription in untransfected BHK21 cells, BHK-PPI-C16 cells, the glucokinase and glucokinase/GLUT2 co-expressing cell populations generated from BHK-PPI-C16. Approximately 5 ng of the appropriate cDNA and $\mathrm{H}_{2} \mathrm{O}$ were used as the positive and negative controls, respectively. MW indicated molecular weight markers.

of staining in the parental BHK21 cell line. Immunocytochemical analysis for GLUT2 and glucokinase was not as clear due to the expression of these proteins in the untransfected cells. There is no noticeable increase in the intensity of the DAB staining for these antigens in the transfected populations as a whole; there does appear however to be individual intensely stained cells within the transfected population but not in the control. The mouse $\beta$ cell line, Min6, was used as a positive control in these analyses. 

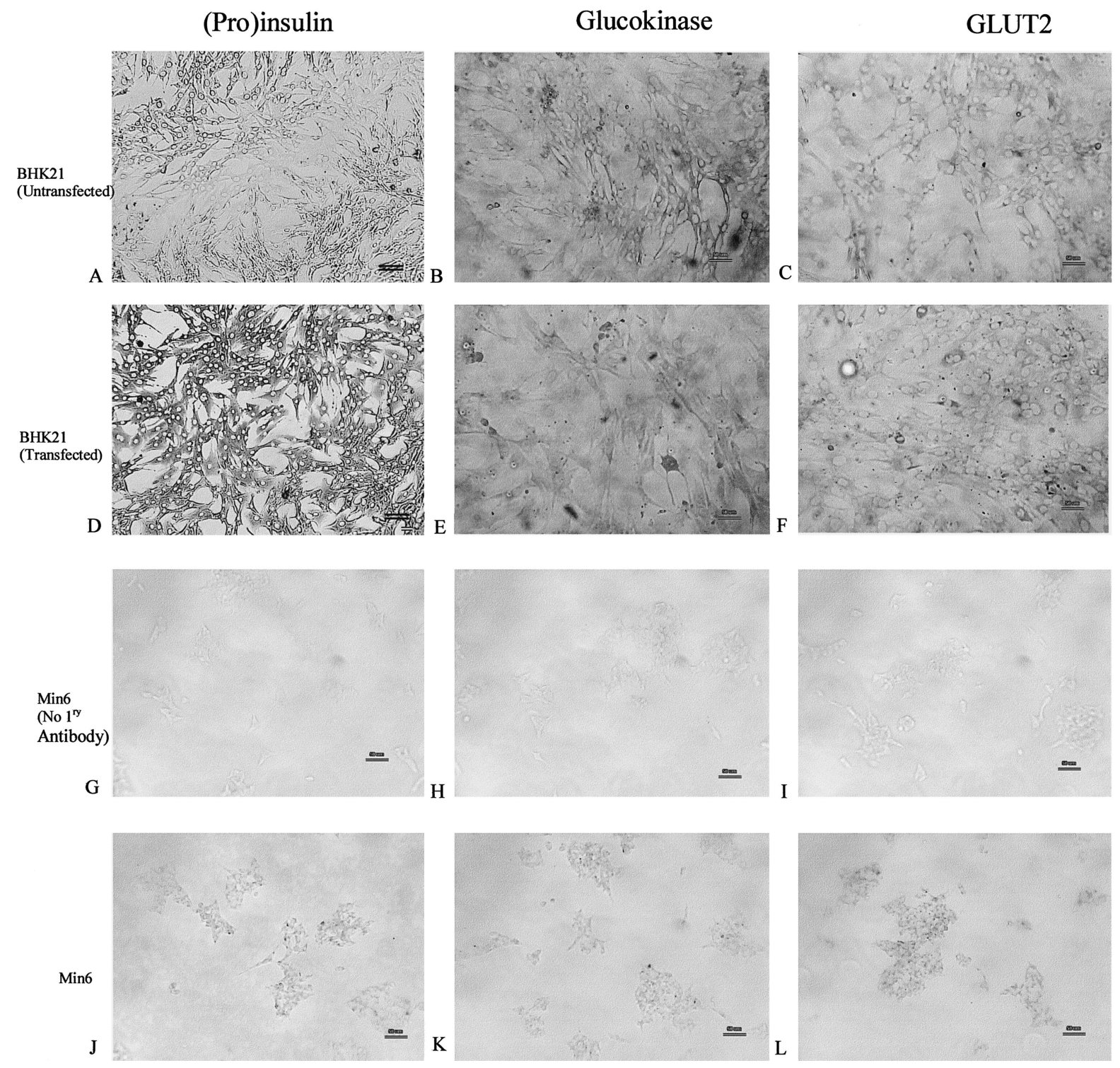

Figure 2. Immunocytochemistry for proinsulin (A, D, G, J), glucokinase (B, E, H, K) and GLUT2 (C, F, I, L) in untransfected cells (A, B, C), transfected cell populations BHK-PPI-C16 (D), BHK-PPI-C16-GCK (E), BHK-PPI-C16-GCK-GLUT (F) and Min6 cells (J, K, L). The presence of the protein is indicated by the positive staining. The possibility of non-specific staining by the secondary antibody was repudiated

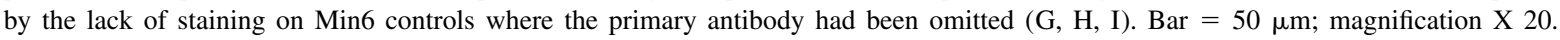

\section{Western Blot analysis}

\section{Glucokinase}

As shown in Figure 3A, a single band for glucokinase protein was detected at $50 \mathrm{kDa}$. This protein was detected in non-transfected BHK-PPI-C16 cells and in both of the cell populations transfected with the glucokinase cDNA (BHK-PPI-C16-GCK and BHK-
PPI-C16-GCK-GLUT). Densitometric analysis, using $\beta$-actin as an endogenous control, did not indicate a significant increase in levels of this protein in either of the transfected populations. DLKP was used as a positive control in these experiments.

\section{GLUT2}

Single bands (approximately $60 \mathrm{kDa}$ ) corresponding 


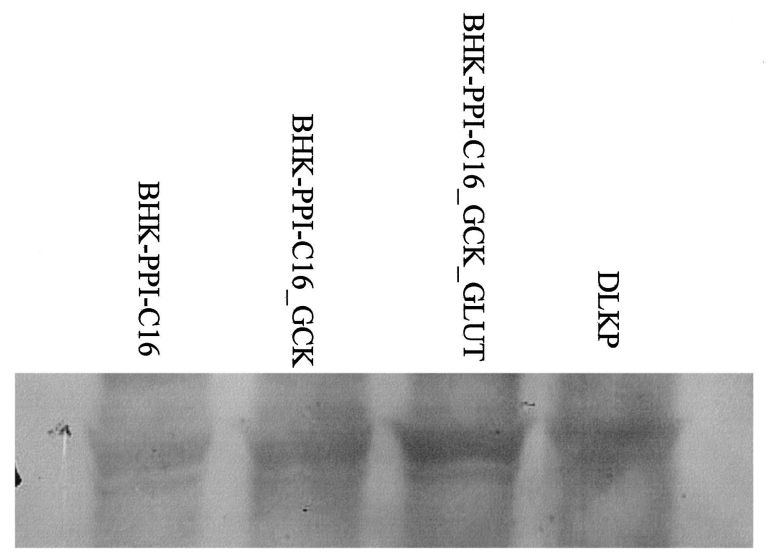

GCK $(50 \mathrm{kDa})$

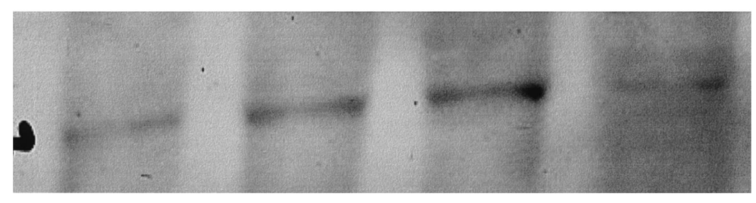

$\beta$ Actin $(44 \mathrm{kDa})$

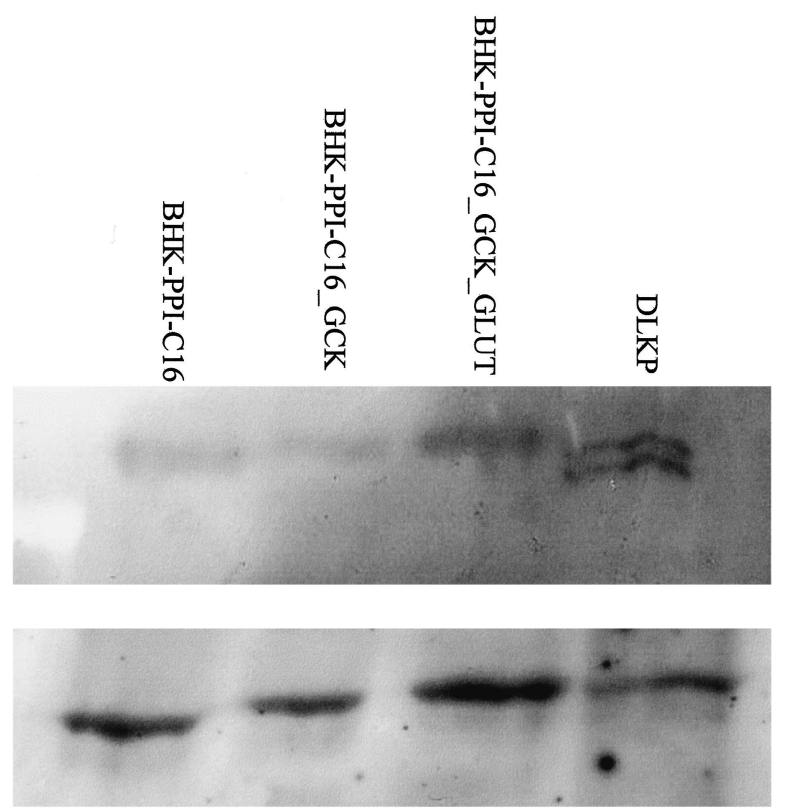

GLUT2 $(60 \mathrm{kDa})$

$\beta$ Actin $(44 \mathrm{kDa})$

Figure 3. Western blot analysis of (A) glucokinase and (B) GLUT2 protein expression in the untransfected BHK-PPI-C16 cells and in the transfected populations. $50 \mu \mathrm{g}$ of cellular lysate was subjected to polyacrylamide gel electrophoresis (PAGE), transferred onto nitrocellulose and probed with (A) goat anti glucokinase (Santa Cruz, Biotech) and (B) rabbit anti GLUT2 (Chemicon). Glucokinase expression was present in all BHK cell lines tested and densitometry using $\beta$-actin as a control did not indicate a significant difference in protein levels. GLUT2 expression was present in all cell lines tested and again was not significantly increased in the transfected populations. DLKP was used as a control lysate in both cases. The gels presented are representative blots of at least three independent experiments.

to GLUT2 protein were detected in BHK-PPI-C16, BHK-PPI-C16-GCK, the transfected population BHK-PPI-C16-GCK-GLUT and in the positive con- trol cell line, DLKP (Figure 3B). Densitometric analysis of a number of blots did not indicate a significant increase in GLUT2 protein levels in the transfected 
population when normalised for levels of the endogenous control $\beta$-actin.

\section{ELISA analysis}

Constitutive secretion and storage of proinsulin Proinsulin ELISA was used to determine the levels of proinsulin/insulin secreted and stored by BHK-PPIC16. Over a $24 \mathrm{~h}$ period the BHK-PPI-C16 cells were found to secrete proinsulin at a rate of $0.12 \mathrm{pmol} /$ hour $/ 10^{5}$ cells while the cellular proinsulin content was relatively constant at $0.36 \mathrm{pmol}^{-1} \pm 0.04$ (Figure 4). Thus the cells were secreting approximately $34 \%$ of their proinsulin each hour. The constitutive release of proinsulin from BHK-PPI-C16 has been stable for more than 12 mo. Use of a specific ELISA for processed human insulin indicated that there was no secretion or storage of any mature human insulin.

Glucose stimulated insulin secretion

BHK-PPI-C16 was found to be insensitive to the levels of glucose in the surrounding environment over the entire physiological range (Figure 5A). The cell population expressing GCK (BHK-PPI-C16-GCK) demonstrated an almost two fold increase in proinsulin secretion at 2-5 $\mathrm{mM}$ glucose when compared to basal medium. Proinsulin secretion was undetectable in the BHK-PPI-C16-GCK-GLUT population (Figure 5B).

cAMP mediated stimulated secretion

Secretion of proinsulin from BHK-PPI-C16 was in- creased in the presence of agents designed to increase cAMP. 3-isobutyl-methylxanthine (IBMX) and glucagon resulted in maximal stimulation (approximately 2 fold) over a 2-hour period of exposure (Figure 6).

\section{Discussion}

The data presented in this study demonstrate that the fibroblast cell line BHK21 can be engineered to produce and secrete human proinsulin in a single manipulation. As reported in other studies with fibroblasts (Taniguchi et al. 1997), the release of proinsulin from BHK-PPI-C16 was constitutive and was not accompanied by any traces of mature processed insulin. These cells do not have the endopeptidase enzymes, PC2 and PC3, and thus were unable to process the proinsulin formed to mature insulin.

For non- $\beta$ cell replacement therapy to be successful there must be minute to minute regulation of the patients blood glucose levels over the entire physiological range. It was found however that the BHKPPI-C16 cells were insensitive to glucose levels in the surrounding environment. These cells were found to contain low levels of the two critical components of the glucose sensing system (GLUT2 and glucokinase) thus these cDNAs were transfected in to the BHKPPI-C16 proinsulin expressing cells. There did not appear to be significant translation of the transfected cDNAs, yet there were effects on insulin secretion. Expression of the glucokinase gene alone led to a

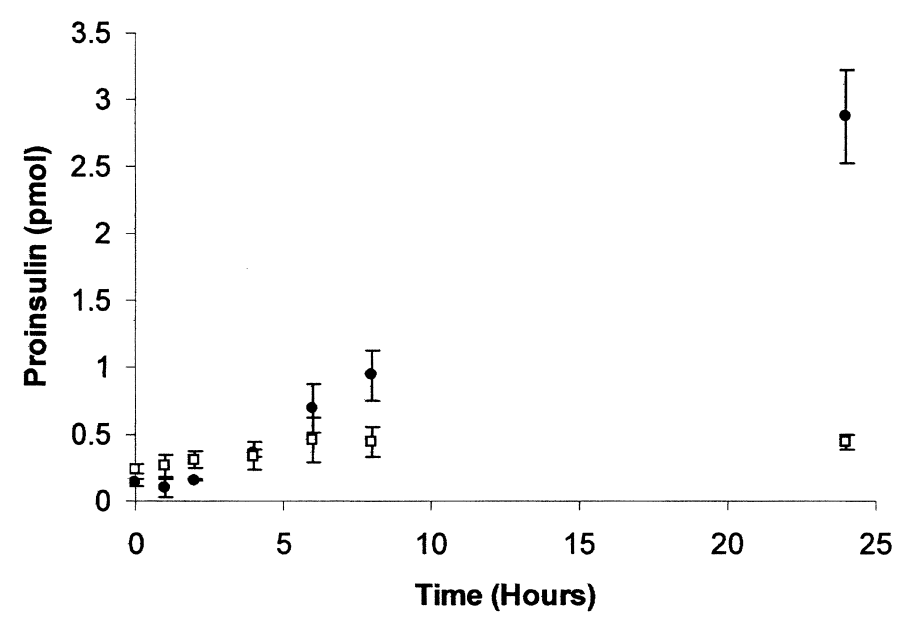

- Medium Proinsulin (pmol)

- Lysate Proinsulin (pmol)

Figure 4. Proinsulin secretion and storage over a 24 hour period as measured by proinsulin ELISA. There was no processed human insulin in either the medium or the cellular lysates as measured using an ELISA for processed human insulin. The data represent the means \pm SD of at least three independent experiments. 

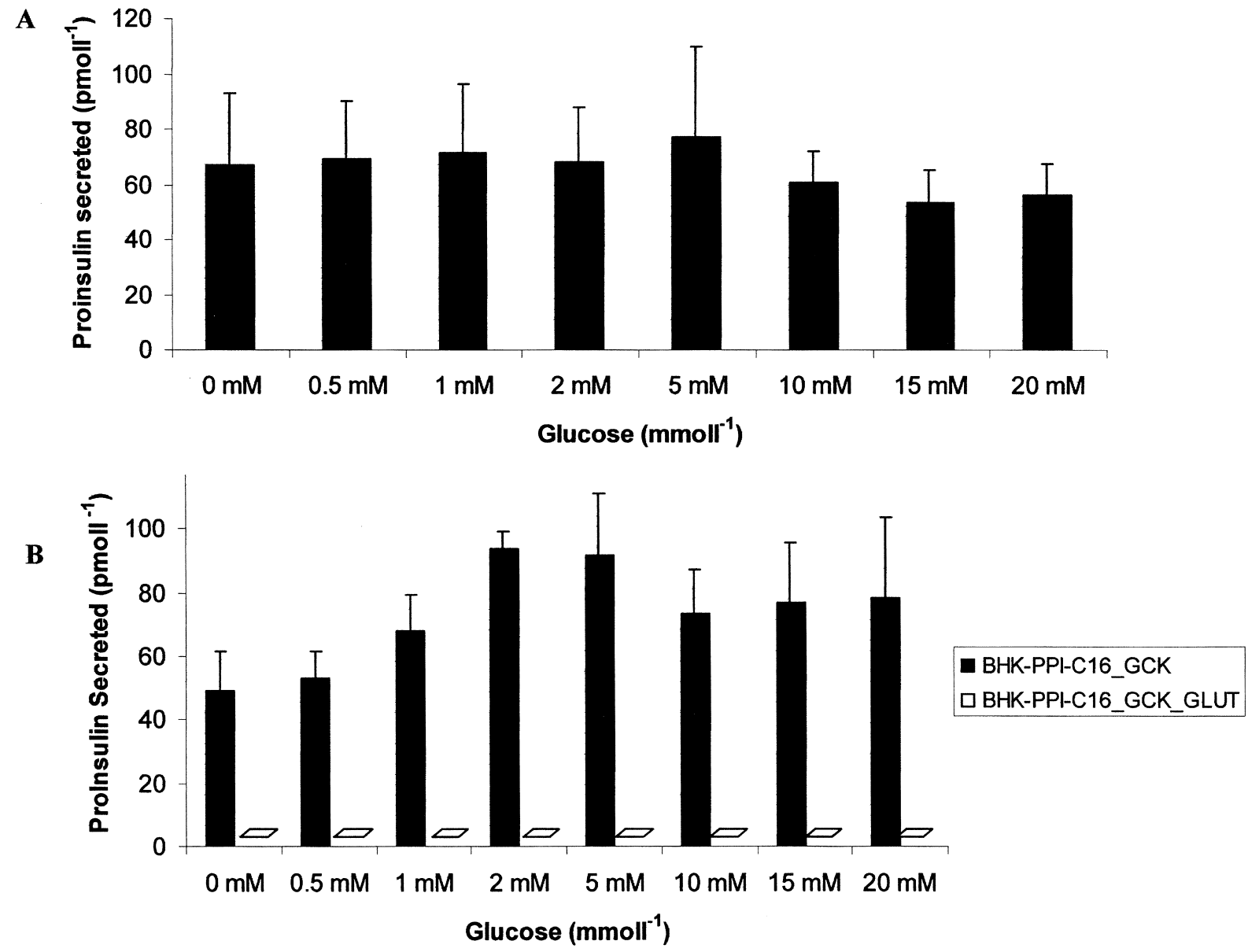

Figure 5. Proinsulin release from (A) BHK-PPI-C16 and (B) the glucose sensor transfected populations BHK-PPI-C16-GCK and BHK-PPIC16-GCK-GLUT. Proinsulin release was measured from cells incubated with glucose concentrations over the range $0-20 \mathrm{mmol} 1^{-1}$ for $2 \mathrm{~h}$. The data represent the means $\pm \mathrm{SD}$ of at least three independent experiments.

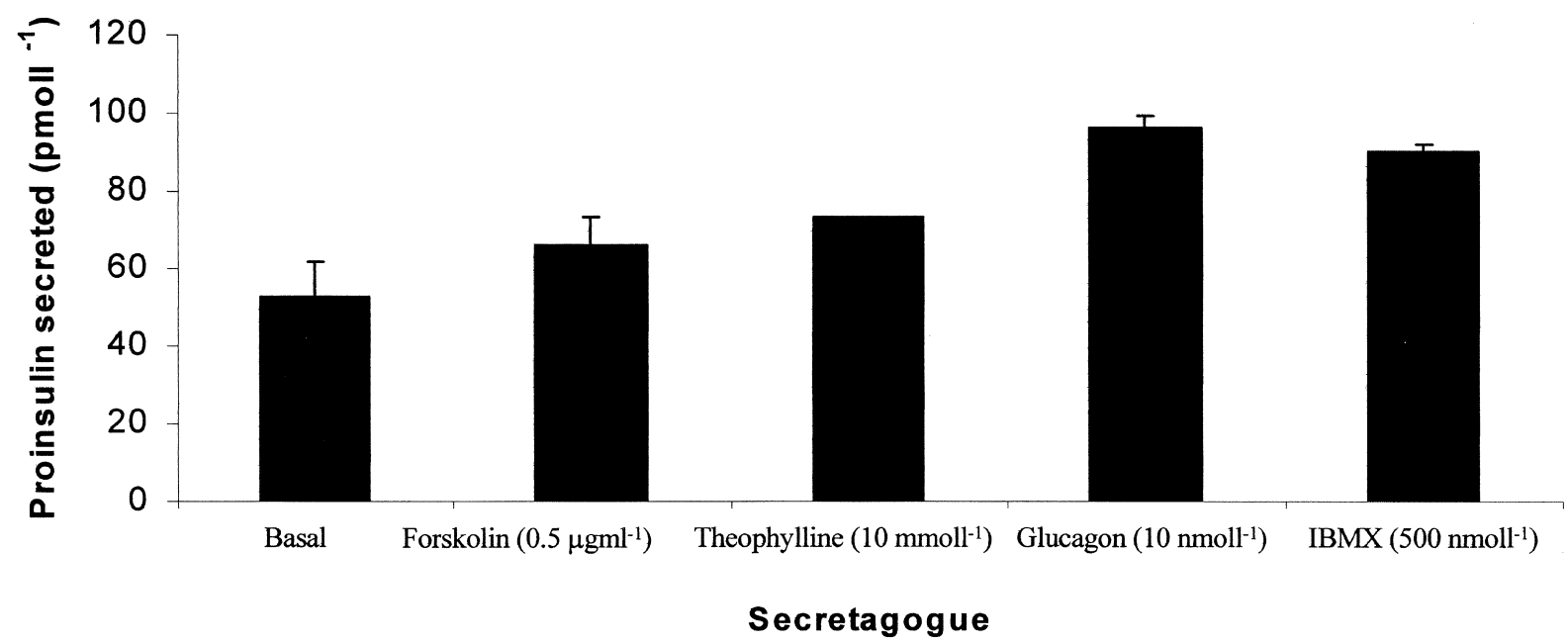

Figure 6. Induction of proinsulin release from BHK-PPI-C16 incubated with cAMP inducing agents for $2 \mathrm{~h}$. The data presented \pm SD is representative of at least three independent experiments. 
2-fold stimulation of proinsulin secretion at approximately $2 \mathrm{mmol}^{-1}$ glucose. This is below the physiological range of glucose concentrations that a $\beta$ cell would respond to (minimal stimulation occurs at approximately $4-5 \mathrm{mmol} \mathrm{l}^{-1}$ ). There is an apparent decrease in proinsulin secretion at glucose levels in excess of $5 \mathrm{mmol}^{-1}$ indicating perhaps that the cells are sensitive to glucose at high levels. A similar decrease in insulin secretion following maximal stimulation at subphysiological levels has been found to occur in AtT20 cells (Davies et al. 1998). Coexpression of both glucokinase and GLUT2 in the PPI expressing cell line BHK-PPI-C16 led to a complete eradication of insulin secretion while insulin mRNA transcript level was unaffected (Figure 1A).

Recombinant bacteria show altered metabolic and proliferative profiles compared to wild type strains due to the increased metabolic load of expressing the recombinant protein (Lee and Eldin 1985). Recombinant BHK cells were shown to be similarly affected when G418 was present in the growth medium. It was found that G418 caused an increase in the level of the neomycin resistance gene $\left(\right.$ neo $\left.^{r}\right)$ encoded on the expression plasmid. The increased levels of $n e o^{r}$ were found to increase the metabolic load of the BHK cells (Yallop and Svedsen 2001). No effects on growth and metabolism were noted following the expression of the neo ${ }^{r}$ containing pT-PPI plasmid in BHK-PPI-C16 cells. It is possible however that the subsequent transfection of the pcDNA3.1/Zeocin (GLUT2) and the pcDNA3.1/Hygromycin (Glucokinase) increased the metabolic load to such a point that the cells were no longer able to synthesise and secrete proinsulin. This may also explain the poor translation of these transfected proteins despite the large overexpression achieved at the transcriptional level. There was evidence that the general protein expression in BHKPPI-C16-GCK-GLUT was adversely affected following overexpression of the two glucose sensing genes and their associated resistance genes (not shown).

Stimulation of BHK-PPI-C16 with agents that are known to increase intracellular cAMP levels induced secretion of proinsulin as in similar studies (Simpson et al. 1995; Lu et al. 1998; Kintsurashvili et al. 1998). Increased secretion upon stimulation is indicative of storage of the peptide. Immunocytochemical analysis did not reveal the presence of insulin storage granules, rather it was found that the proinsulin was distributed in a diffuse pattern within the cytoplasm (Figure 2). The increased secretion observed upon exposure of BHK-PPI-C16 to cAMP stimulating agents may be as a result of metabolic effects leading to an increase in proinsulin synthesis and thus secretion. This effect has already been described as a characteristic of fibroblasts (Kelly 1985). The stimulation of secretion in the glucokinase expressing population BHK-PPIC16-GCK at $5 \mathrm{mmol}^{-1}$ may be also due to regulation of secretion at the level of availability. This type of regulated secretion would be similar to that achieved in fibroblasts using the inducible promoter system (Kawakami et al. 1992).

In conclusion, BHK21 cells were successfully transfected with the human PPI cDNA, but due to the apparent lack of a regulated storage and secretion pathway and the endopeptidases PC2 and PC 3 , only constitutive secretion of unprocessed proinsulin was observed. These results are similar to those obtained in this laboratory using the Vero fibroblast cell line (O'Driscoll et al. 2002). Co-transfection of glucose sensing genes was insufficient to endow the cells with appreciable glucose sensing capabilities. Thus these cells may be of more use as a means of providing a constant release of proinsulin, provided that the cells could be encapsulated with some biocompatible material to prevent immunological rejection, implant overgrowth and to control the rate of proinsulin secretion. The cells would also have to be cultured under approved serum free conditions such as those described for BHK-21 cells by Merten et al. (1999).

\section{Acknowledgements}

This work was supported by grants from Bio-Research Ireland and Enterprise Ireland.

\section{References}

Aebischer P., Pochon N.A., Heyd B., Deglon N., Joseph J.M., Zurn A.D. et al. 1996. Gene therapy for amyotrophic lateral sclerosis (ALS) using a polymer encapsulated xenogenic cell line engineered to secrete hCNTF. Hum Gene Ther 7: 851-860.

Davies E.L., Shennan K.I.J., Docherty K. and Bailey C.J. 1998. Expression of GLUT2 in insulin secreting AtT20 pituitary cells. J Molec Endocrinol 20: 75-82.

Falqui L., Martinenghi S., Severini G.M., Corbella P., Taglietti M.V., Arcelloni C. et al. 1999. Reversal of diabetes in mice by implantation of human fibroblasts genetically engineered to release mature human insulin. Hum Gene Ther 10: 1753-1762.

Halban P.A. and Irminger J.C. 1994. Sorting and processing of secretory proteins. Biochem J 299: 1-18.

Hughes S.D., Quaade C., Milburn J.L., Cassidy L. and Newgard C.B. 1991. Expression of normal and novel glucokinase 
mRNA's in anterior pituitary and islet cells. J Biol Chem 266: 4521-4530.

Hughes S.D., Johnson J.H., Quaade C. and Newgard C.B. 1992. Engineering of glucose stimulated insulin secretion and biosynthesis in non-islet cells. Proc Natl Acad Sci USA 89: 688692

Kawakami Y., Yamaoka T., Yamashita K., Itakura M. and Nakcuchi H. 1992. Somatic gene therapy for diabetes with an immunological safety system for complete removal of transplanted cells. Diabetes 41: 956-960.

Kelly R.B. 1985. Pathways of protein secretion in eukaryotes. Science 230: 25-32.

Kintsurashvili E., Zhou D., Wheeler M.B., Vacek I. and Sum A.M. 1998. Genetic engineering of glucose stimulated insulin secretion in Chinese hamster ovary cells. Art Cells Blood Subs and Immob Biotech 26: 329-340.

Law E., Gilvarry U., Lynch V., Gregory B., Grant G. and Clynes M. 1992. Cytogenetic comparison of two poorly differentiated human lung squamous cell carcinoma lines. Cancer Genet Cytogenet 59: 111-118.

Lee S.W. and Eldin G. 1985. Expression of tetracycline resistance in pBR322 derivatives reduces the reproductive fitness of plasmid containing Escherichia coli. Gene 39: 173-180.

Lu D., Tamemoto H., Saito I. and Takeuchi T. 1998. Regulatable production of insulin from primary-cultures hepatocytes: insulin production is up-regulated by glucagon and cAMP and down regulated by insulin. Gene Ther 5: 888-895.

Merten O.W., Kallel H., Manuguerra J.C., Tardy-Panit M., Crainic
R., Delpeyroux F. et al. 1999. The new medium MDSS2N, free from any animal protein supports cell growth and production of various viruses. Cytotechnology 30: 191-201.

Motoyoshi S., Shirotani T., Araki E., Sakai K., Kaneko K., Motoshima H. et al. 1998. Cellular characterisation of pituitary adenoma cell line (AtT20 cell) transfected with insulin glucose transporter type 2 (GLUT2) and glucokinase genes: insulin secretion in response to physiological concentrations of glucose. Diabetologia 41: 1492-1501.

O’Driscoll L., Gammell P. and Clynes M. 2002. Engineering vero cells to secrete human insulin. In vitro cell dev biol anim 38: $146-153$.

Selden R.F., Skoskiewicz M.J., Russel P.S. and Goodman H.M. 1987. Regulation of insulin gene expression. implications for gene therapy. New Engl J Med 317: 1067-1076.

Simpson A.M., Tuch B.E., Swan M.A., Tu J. and Marshall G.M 1995. Functional expression of the human insulin gene in a human hepatoma cell line (Hep G2). Gene Ther 2: 223-231.

Stewart C., Taylor N.A., Green I.C., Docherty K. and Bailey C.J. 1994. Insulin-releasing pituitary cells as a model for somatic cell gene therapy in diabetes mellitus. J Endocrinol 142: 339-343. Taniguchi H., Fukao K. and Nakcuchi H. 1997. Constant delivery of proinsulin by encapsulation of transfected cells. J Surgical Res 70: $41-45$.

Yallop C.A. and Svedsen I. 2001. The effects of G418 on the growth and metabolism of recombinant mammalian cell lines. Cytotechnology 35: 101-114. 
